\title{
LA DOMESTICACIÓN DE LA NATURALEZA: DE LA ARTIFICIALIZACIÓN A LA INTERVENCIÓN
}

\section{THE DOMESTICATION OF NATURE: FROM ARTIFICIALITY TO INTERVENTION}

\author{
Andrés MOYA \\ Instituto Cavanilles de Biodiversidad y Biologia Evolutiva, \\ Universitat de València \\ Centro Superior de Investigación en Salud Pública (CSISP), Valencia \\ CIBER en Epidemiología y Salud Pública (CIBEResp)
}

RESUMEN: Darwin tuvo muy presente el paralelismo entre la selección artificial de las especies domesticadas y la selección natural. De hecho, la domesticación de plantas y animales no ha sido otra cosa que el arte de dirigir entes naturales en direcciones determinadas. Pero: ¿hasta dónde hemos llevado este proceso de domesticación? No se trata ya solamente de domesticar otras especies, hemos domesticado muchas otras cosas, desde eso otro que denominamos ambiente hasta nosotros mismos. La ciencia juega un papel creciente en el proceso de domesticación, transitando con racionalización creciente desde una domesticación sin mucho fundamento científico (artificialización) a otra plenamente teorizada (en el sentido de teoría científica), a la que denomino intervención.

PALABRAS CLAVE: Evolución, selección natural, selección artificial, genética, epistemología.

ABSTRACT: Darwin was aware of the parallelism between the artificial selection of domesticated species and natu- 
ral selection. In fact, the domestication of plants and animals is nothing more than the art to drive natural entities in a predetermined direction. But: to what extent have we conducted the domestication process? It is not only the case that we have domesticated other species, but many other entities, including us. Science plays an important role in this process of domestication, a process of an increasing rational content that started with a domestication with little scientific background (artificiality) until the current one that shows a profound theoretical content (in the sense of scientific theory), that I call intervention.

KEYWORDS: Evolution, natural selection, artificial selection, genetics, epistemology.

\section{Selección natural}

Quizás el tema más controvertido relacionado con la biología evolutiva haya sido, y siga siendo, el de la importancia que en el proceso evolutivo ha tenido la selección natural. Sostengo que en torno a esta problemática hay dos cuestiones que son, por lo menos en parte, diferentes. En primer lugar hay que responder a la pregunta sobre la importancia de la selección natural como proceso de distribución de la variabilidad fenotípica observada en los seres vivos; y en segundo lugar es también imprescindible determinar si el proceso evolutivo es comprensible haciendo uso exclusivamente de una teoría variacional o, por el contrario, es necesario formular teorías del desarrollo que puedan dar cuenta de los fenómenos que originan la variabilidad fenotípica. Ambos problemas pueden tener, en principio, distintas soluciones científicas.

Hasta donde sabemos, la noción de evolución y de cambio ya aparece en los primeros filósofos griegos, concretamente Heráclito y Anaximandro. Y es también una idea fundamental en la mayoría de imágenes míticas del Universo. Cambio y evolución son conceptos que están ligados a la experiencia ordinaria del ser humano, lo que no quiere decir que dispongamos de explicaciones racionales de los mismos. Conocidos naturalistas franceses como Buffon, Lamarck, Saint-Hilaire, o el mismo abuelo de Darwin, Erasmus Darwin, habían dedicado parte de su vida a la investigación y especulación sobre el carácter evolutivo de los seres vivos. 
¿Por qué, entonces, la teoría de la evolución significa Darwin en nuestros días? La respuesta más inmediata, aunque quizá menos informativa, es que la teoría de la evolución comúnmente aceptada es, en gran medida, la formulada por Darwin. Si bien la teoría darwiniana de la evolución data de 1859, muchos de los evolucionistas actuales se consideran darwinistas. Entre otros meritos, el éxito de la teoría de Darwin se debe a su propuesta de un proceso no teleológico que da cuenta de la transformación de las especies: la selección natural (Reichenbach 1967). A excepción de los creacionistas, casi nadie duda del hecho de la evolución. En nuestros días es oportuno distinguir entre tal hecho y si la supuesta causa que la promueve es la selección natural.

De todos modos, la mitología con la que suelen ser acondicionados ciertos episodios de la historia de la ciencia puede producir hoy la creencia de que, desde su formulación, la teoría de la evolución por selección natural, como teoría científica que es, sólo tuvo que batirse con las imágenes religiosas de la naturaleza. Pero esta creencia se encuentra bastante alejada de la realidad (Bowler 1985).

Prácticamente desde el momento de su presentación, la teoría de la evolución por selección natural ha sido objeto de grandes elogios pero también de fuertes críticas. El estatus epistemológico de la teoría de la selección natural ha sido insistentemente objeto de polémica. La imagen darwiniana de la evolución, sin embargo, resulta inmensamente atractiva, habiendo sido extendida $-\mathrm{y}$ no solo por los deterministas biológicos - a la evolución cultural en general (Toulmin 1977). Muchos han sido, también, los intentos por encontrar qué puede haber en la idea de selección natural que la haga tan problemática.

Es bastante antigua la creencia en que los seres vivos se encuentran adaptados a su medio. Explicaciones teleológicas y/o teológicas han intentado dar cuenta de esta observación. Y se sabía también, sin lugar a dudas, que hay mayor parecido físico entre parientes que entre individuos no emparentados. De hecho Platón y posteriormente Campanella propusieron la puesta en práctica de programas eugenésicos porque pensaban que los caracteres humanos eran heredables y, por tanto, se podían aplicar sobre ellos la selección artificial. A finales del siglo XIX y principios del XX estas tesis eugenésicas fueron defendidas por el primo de Darwin, Francis Galton. 
Herencia y adaptación son dos conceptos que se encuentran en la base de la teoría darwiniana de la evolución. Darwin en El origen de las especies describe del modo siguiente lo que entiende por selección natural:

¿podemos dudar — y recordemos que nacen muchos más individuos de los que es posible que sobrevivan- de que los individuos que tengan cualquier ventaja, por ligera que sea, sobre otros, tendrían más probabilidades de sobrevivir y de procrear su especie? Por el contrario, podemos estar seguros de que toda variación perjudicial, aún en el grado más ínfimo sería rigurosamente destruida. A esta conservación de las variaciones y diferencias individualmente favorables y la destrucción de las que son perjudiciales, la he llamado selección natural o supervivencia de los más aptos. Las variaciones que no son útiles ni perjudiciales no serían afectadas por la selección natural, y quedarían abandonadas ya a un elemento fluctuante, como vemos quizá en ciertas especies polimorfas, o bien llegándose a fijar finalmente, a causa de la naturaleza del organismo y de la naturaleza de las condiciones del medio ambiente (Darwin 1859, 115-116).

Por otro lado Darwin ve un paralelismo entre la selección natural y la artificial. Examinemos la relación entra ambas con un ejemplo. El hombre ha elimina de sus cultivos las malas hierbas, a mano o con instrumentos apropiados. Este procedimiento depende de la capacidad del agricultor para distinguir, obviamente, lo que son malas hierbas de la planta o plantas que le interesa cultivar. En muchos casos la labor no posee inconvenientes especiales, pero en ciertas ocasiones aparecen cizañas complicadas, porque son miméticas de las plantas que se cultivan. Es más, muchas veces estas plantas hibridan con el cultivo de interés y producen descendencia viable. ¿Qué hacer en estos casos? Para acabar con ciertas cizañas miméticas del arroz los agricultores introdujeron en su momento variedades de arroz que poseían hojas de color púrpura. Como la escarda se hacía a mano los agricultores podían distinguir fácilmente entre el arroz y la cizaña. Ahora bien, y debido a la hibridación, los agricultores seleccionaban involuntariamente aquellos híbridos que poseían hojas de color púrpura, de forma que en al cabo de pocas cosechas toda la cizaña de los respectivos arrozales era de hojas púrpura e indistinguible de las plantas de arroz cultivado. Poseer hojas de color púrpura es un carácter que se selecciona (artificial, pero involuntariamente), que confiere a sus portadores mayor probabilidad de supervivencia. Puesto que dicha característica es heredable, las cizañas acabarán teniendo todas hojas de color púr- 
pura. Este ejemplo pretende marcar el paralelismo entre selección artificial y natural. De hecho se trata de un caso de selección artificial que, al realizarse de forma involuntaria, podría considerarse como de selección natural.

Es oportuno manifestar aquí la deuda que Darwin reconoció tener con Malthus. La obra de Malthus sobre la demografía humana y el aumento del número de individuos de la especie en un medio donde los recursos son limitados, le convenció a Darwin, sobre todo, de que en la naturaleza la lucha por la existencia equivalía a la selección artificial practicada por los humanos. En efecto, no todos los individuos de nuestra especie tenían igual acceso a esos recursos y por lo tanto, solo aquellos que accedieran a ellos se perpetuarían.

\section{Herencia}

Cuando Darwin publicó El origen no se había formulado todavía teoría de la herencia alguna que fuera mayoritariamente aceptada. Y aunque el trabajo original de Mendel es de 1865, no fue tenido en cuenta por la comunidad científica hasta 1900, año en el que fueron redescubiertas las leyes de la herencia conocidas como las leyes de Mendel. Darwin era partidario de una teoría de la herencia conocida como pangénesis, según la cual los responsables de la herencia eran unas partículas llamadas gémulas que circulaban por todo el cuerpo. Francis Galton, muy interesado en todos los problemas relacionados con la herencia, sometió a contraste la hipótesis. Si un conejo, razonó Galton, recibe una trasfusión de sangre, sus hijos tendrán características del conejo donante. Llevó a cabo a experiencia y los resultados fueron negativos para la teoría. A falta de una explicación biológica de la herencia, Galton se puso a trabajar para encontrar una ley matemática que relacionara la distribución de un carácter concreto en las generaciones filial y paterna. Es así como llegó a formular la ley de la herencia ancestral, donde el padre transmite, en promedio, la mitad de su naturaleza, el abuelo un cuarto, el bisabuelo un octavo. Es decir, la participación decrece en proporción geométrica.

En el siglo XIX existía una gran confusión entre fenómenos como la reversión, la variabilidad y la herencia. En este contexto, el gran mérito de Galton fue proporcionar una definición operativa de herencia, que permitía hacer investigación sobre ella. La ley de la herencia ancestral constituye uno de los prime- 
ros pasos de la genética cuantitativa y está relacionada con las técnicas de los mejoradores de las especies domésticas. Algunas técnicas tradicionales jugaron un papel importante en la formulación de las teorías sobre la herencia. También Mendel comienza su conocido artículo haciendo referencia a la técnica tradicional:

La experiencia de la fecundación artificial, tal como se realiza en plantas ornamentales para obtener nuevas variaciones en el color, ha conducido a los experimentos que se van a describir aquí. La notable regularidad con que reaparecen siempre las mismas formas híbridas cuando la fecundación se realiza entre las mismas especies, indujo a ulteriores experimentos, cuyo objeto fue seguir el desarrollo de los híbridos y su descendencia (Mendel 1866, 1).

Cuando a principios de siglo XX se redescubrieron las leyes de Mendel se desató una fuerte polémica en el seno de la genética entre mendelianos y biómetras, entre quienes creían que la evolución se producía a partir de la variación discontinua (mutaciones) y los que pensaban que era la selección natural la que, a partir de la variación continua, conducía a la evolución. Hacia finales de la primera década del siglo XX había trabajos experimentales, como los de NilssonEhle y Murray East, que demostraban que la herencia mendeliana podía demostrar la variación continua. El conocido artículo de Fisher de 1918 puede entenderse como un intento por transformar el mendelismo en una herramienta apropiada para la biometría. Pero no solo para la biometría, sino también para la eugenesia. La intención de Fisher no consistió solo en reconciliar mendelismo y biometría, sino hacer uso del mendelismo para vindicar el programa biométrico y eugenésico. El trabajo de Fisher fue claramente pionero, para abrir lo intensos debates que se han suscitado posteriormente en torno al papel relativo del ambiente versus la herencia en relación con los caracteres biológicos.

La solución matemática de Fisher mostraba cómo la varianza observada en una población respecto a la distribución de un carácter podía ser debida a la combinación de numerosos factores genéticos y ambientales. Suponiendo que un carácter cuantitativo estuviese determinado por un gran número de genes mendelianos, la varianza genética podría descomponerse en varianza genética aditiva y no aditiva. A Johanssen se debe el modelo $F=G+A$, donde $F$ representa el fenotipo, $G$ el genotipo y $A$ el ambiente. En 1917, Sewall Wright descompuso 
la varianza fenotípica en varianza debida a factores ambientales y varianza debida a factores genéticos. Pero Wright no analizó la varianza genética en sus componentes aditivos y no aditivos, como sí hizo Fisher. No es aditiva la varianza genética debida, por ejemplo, a la dominancia o a la epistasia. En estos dos casos, un mismo cambio genético produce efectos distintos en el fenotipo.

Posteriormente, en 1936, Fisher definió el concepto de heredabilidad (en sentido estricto) como la razón entre la varianza aditiva y la fenotípica. La solución planteada por Fisher, donde un carácter cuantitativo está determinado por un número dado de genes mendelianos, mostraba la compatibilidad de la genética mendeliana con la teoría de la selección natural, lo que debe considerarse como uno de los primeros pasos dados en el camino hacia la síntesis evolutiva, o neodarwinismo, que se llevará a cabo en los años treinta del siglo XX. Curiosamente el término neodarwinismo fue acuñado por Weismann y la expresión síntesis evolutiva por Julian Huxley.

\section{Selección natural y evolución}

La selección natural puede ser definida como un proceso en el que deben cumplirse una serie de condiciones (Endler 1986). Así, en una población donde: a) existe variación entre los individuos respecto de algún carácter; es decir, el carácter se presenta en formas o estados (continuos o discretos); b) se da una relación consistente entre el estado del carácter y la capacidad para el apareamiento, capacidad fertilizadora, fertilidad, fecundidad y/o capacidad para sobrevivir; es decir, existen diferencias de eficacia biológica entre los individuos en función de la variabilidad fenotípica del carácter (diferentes estados del carácter suponen diferentes eficacias biológicas para los individuos portadores); y c) se presenta una relación consistente para el carácter en cuestión entre padres e hijos, relación que es parcialmente independiente de los factores ambientales; es decir, en la población en cuestión la variación fenotípica es, por lo menos en parte, heredable; entonces 1) más allá de los esperado teniendo en cuenta la ontogenia, la distribución de los estados del carácter diferirá entre clases de edad; y 2) si la población no está en equilibrio, entonces la distribución de los estados del carácter en la generación filial será diferente, de forma predecible, a la observada en la generación paterna más allá de los esperado por la exclusiva actuación de (a) y (c). 
Endler afirma que la selección natural es un proceso tal que, si es el caso que se presentan los fenómenos descritos en (a), (b) y (c), entonces ocurre el fenómeno descrito en (1) y (2).

Podríamos pensar en otras posibles presentaciones del concepto y llegar a la conclusión de que todas ellas son matices o apreciaciones formales en el sentido de que las discrepancias en las definiciones no pasan de ser meras disputas sobre la forma. Pero, en ocasiones, hay razones importantes de fondo que pueden estar en la base de las diferencias. En el caso de Endler existe un claro interés de cambiar la imagen del proceso evolutivo producida por la aplicación sistemática del modelo de la genética de poblaciones al que se ha aludido en el apartado anterior. Examinemos las divergencias frente a ella de lo que podríamos denominar la concepción de la selección natural que subyace a la ecología evolutiva. Para Endler las condiciones (a) y (b) son necesarias para que haya selección fenotípica, y las condiciones (a), (b) y (c) para que se de la selección natural. Entonces, la selección natural es un proceso que ocurre cuando se dan diferencias heredables entre los organismos. En otras palabras, mientras que para Endler el cambio en la distribución de los estados del carácter o de los genes, ya existentes, no es evolución, esto es, ni (1) ni (2) son, por ellos mismos evolución, para los neodarwinistas sí.

El punto crucial en las consideraciones de Endler es el relativo al origen de los alelos, variantes, valores o estados de carácter. Mientras que la teoría clásica de la selección natural o de la deriva genética no necesita hacer referencia al origen de la nueva variación o a la estructura de los sistemas genéticos, según Endler la teoría de la evolución sí debiera hacerlos. Para Endler la evolución no consiste en el cambio de las frecuencias de los genes en las poblaciones, sino en el cambio direccional y/o acumulativo de las características de los organismos.

\section{Variación}

Para entender algunos de los problemas que subyacen a las definiciones de Endler es interesante recordar aquí la distinción, ya clásica, de Sober (1984), siguiendo a Lewontin, entre teorías del desarrollo y teorias de la variación o variacionales. Según Sober el cambio fundamental introducido en la lógica de la explicación del proceso evolutivo por la teoría de la selección natural es que la variación en la naturaleza no sólo es algo que debe ser explicado, sino que es un 
principio explicativo por derecho propio. La selección natural, sostiene Sober, no es exclusivamente una nueva forma de explicar la evolución; es, sobre todo, una nueva forma de explicación, fruto de una conceptualización, en términos poblacionales, de los problemas que deben ser resueltos. Veamos cual es su argumentación a este respecto exponiendo uno de sus propios ejemplos.

Supongamos que en una habitación tenemos un grupo de niños capaces de leer con un grado de soltura similar. De acuerdo con Sober, podemos explicar este hecho de dos modos diferentes. Desde el punto de vista del desarrollo, la explicación tendría en cuenta las experiencias infantiles de cada uno de los niños, los procesos de instrucción a los que han sido sometidos, etc. La explicación variacional, sin embargo, daría cuenta de por qué la habitación contiene únicamente niños que pueden leer con tanta facilidad: en dicha habitación han sido incluidos sólo los individuos con determinado grado de habilidad lectora. Ambos tipos de explicación, afirma Sober, dilucidan por qué todos los niños de la habitación poseen la misma capacidad de leer, pero lo hacen de forma diferente.

Para Sober la mayor contribución del darwinismo fue precisamente la introducción en la explicación de la evolución del paradigma variacional, que se caracteriza por cierto tipo de antirreduccionismo: la explicación del cambio en un conjunto de objetos no tiene que hacer necesariamente referencia a los cambios que se producen en los objetos que componen el conjunto. Una población de organismos puede cambiar aunque los individuos permanezcan siempre estáticos. Según Sober, es la tesis de que la selección natural (en la escala de los organismos individuales) es el proceso principal en la evolución biológica la que sugiere la posibilidad de no recurrir a una teoría sobre el desarrollo. Si la selección natural es el componente principal del proceso evolutivo en las múltiples escalas en las que éste puede detectarse, no hay lugar, por ejemplo, para la intervención de fenómenos como el de las constricciones endógenas (que nos ocuparán en un momento).

Conviene hacer una aclaración antes de continuar. El término desarrollo evoca la existencia de patrones preestablecidos de cambio. Y la mayoría de las teorías del desarrollo siguen este esquema. Así, por ejemplo, son teorías del desarrollo que hacen referencia a patrones preestablecidos el psicoanálisis de Freud, según el cual hay una serie de fases que se suceden una a otra en un orden determinado (oral, anal y genital), o la psicología evolutiva de Piaget (sensoriomotora, pre- 
conceptual, operacional y formal). Pero aquí utilizo la expresión teorías del desarrollo en un sentido derivado y más general. En el ámbito de la evolución biológica utilizo dicha expresión para referirme a cualquier teoría sobre el origen de la variabilidad fenotípica.

\section{Selección natural y teoría de la evolución}

El tema del origen de la variabilidad, al que Endler otorga tanta importancia para la comprensión del proceso evolutivo, tiene relación con la distinción entre los dos tipos de explicación desarrollados por Sober. Es algo que se entenderá más fácilmente si analizamos el caso paradigmático de la teoría de las constricciones o restricciones endógenas.

Para algunos autores muchos caracteres de los seres vivos sólo pueden explicarse mediante la participación tanto de la selección natural como de las restricciones impuestas por el desarrollo embrionario. $\mathrm{Si}$, por ejemplo, los primeros vertebrados terrestres tenían cuatro patas, no era debido - se sostiene- a que este sistema de locomoción fuera el más eficaz, sino porque estos animales descendían de peces que poseían cuatro aletas. Este es un problema sobre el origen de la nueva variabilidad (en el sentido de Endler) que posiblemente solo quepa explicar mediante una teoría del desarrollo (en el sentido de Sober). Otro tanto ocurre en lo referente a la especificidad de los sistemas genéticos. Pequeñas mutaciones en genes relacionados con el ritmo de los acontecimientos en las primeras etapas del desarrollo de un organismo pueden llegar a producir cambios sustanciales en el fenotipo del organismo adulto.

El neodarwinismo, como paradigma de teoría variacional que es, no ha visto como problemático el origen de la variabilidad fenotípica. Ha asumido, de hecho, que existe suficiente variabilidad como para responder a la totalidad de las presiones selectivas. Sin embargo, cada día parece estar más claro que, en caso de tener en cuente el origen de la variabilidad, la imagen del proceso evolutivo podría llegar a ser sustancialmente diferente de la proporcionada por el neodarwinismo.

Con todo, si bien en la actualidad poseemos una gran cantidad de información, procedente fundamentalmente del campo de la genética molecular del desa- 
rrollo, acerca del origen de la variabilidad y la estructura de los sistemas genéticos, seguimos sin tener una idea precisa respecto de la influencia que estos fenómenos han tenido sobre la evolución de los seres vivos. En la mayoría de los casos no se trata más que de conjeturas. Desde mi punto de vista, sin embargo, éste es uno de los aspectos más sorprendentes e interesantes de las polémicas desatadas en los últimos años en torno a las disciplinas evolutivas.

Quienes han defendido la hipótesis según la cual las restricciones endógenas juegan un papel importante en el proceso evolutivo han ilustrado sus concepciones con un escaso número de ejemplos. Lo importante es el gran eco que, pese a estas limitaciones, dichos autores han tenido en la comunidad científica. Es muy probable que esto sea explicable, más que por las virtudes de las hipótesis propuestas, por el reconocimiento de alguna de las insuficiencias del modelo evolutivo generado por la genética de poblaciones.

La distinción de Sober entre los dos tipos de explicación, la variacional y la del desarrollo, puede ser de gran ayuda para comprender algunos aspectos relevantes de las polémicas desatadas en el seno de la biología evolutiva en tiempos recientes. En términos generales, hoy se suele distinguir entre tres concepciones principales del fenómeno evolutivo: la neodarwinista, la neutralista y la que hace referencia a las restricciones endógenas. Sin embargo, aunque las tres teorías pretenden dar cuenta del mismo fenómeno, el proceso evolutivo, en mi opinión la oposición se produce en diferentes escalas. Tanto el neodarwinismo como la teoría neutralista de la evolución molecular son teorías claramente variacionales. Requieren variabilidad, pero ésta no condiciona los procesos de selección natural ni deriva aleatoria. Entre el neodarwinismo y la teoría neutralista solo existe un punto de conflicto: o bien la evolución está promovida por la selección que opera cuando se presentan diferencias de eficacia biológica o se produce de forma aleatoria.

El caso de la teoría de las restricciones endógenas es, como hemos visto, diferente. Los partidarios de esta concepción sostienen que para comprender el proceso evolutivo es pertinente, además de una teoría variacional (la de la selección natural, por ejemplo), una teoría del desarrollo filogenético que tenga en cuenta el problema del origen de la variabilidad. Algunos de los evolucionistas contemporáneos que no se encuentran muy cómodos con la visión neodarwinista del proceso evolutivo apuestan claramente por una teoría de la evolución en la 
que las consideraciones respecto del origen de la variabilidad fenotípica tengan también un lugar.

Por tanto, la oposición que puede establecerse en nuestros días entre las tres concepciones a las que antes hacía referencia sobre el proceso evolutivo no es simétrica. Mientras que según el neodarwinismo y la teoría neutralista de la evolución molecular la evolución puede ser explicada exclusivamente por una teoría variacional, para los partidarios de las restricciones endógenas es necesario, además, el conocimiento sobre el modo en que se produce la nueva variabilidad.

La pregunta relativa al lugar que ocupa el proceso de la selección natural dentro del proceso evolutivo, y por consiguiente, también la pregunta sobre la importancia de la selección natural en la teoría evolutiva, deben clasificarse en dos grandes grupos. El proceso evolutivo consta, principalmente, de dos conjuntos de fenómenos: uno relativo a las fuentes de variación, y otro concerniente a los procesos de distribución (acumulación y dispersión) de la variación. Así, el primer grupo de preguntas concierne a si para la comprensión del proceso evolutivo es suficiente con el conocimiento sobre los procesos de distribución de la variabilidad. El otro grupo de preguntas inquiere si el proceso de selección natural es el proceso de distribución de la variabilidad más importante.

En consecuencia parece claro que, a fin de determinar la relevancia de la selección natural en la evolución es necesario, en primer lugar, dejar claro si la selección natural es, o no, el proceso más importante de distribución de la variación. La deriva genética, como ya he tenido oportunidad de mostrar, también da cuenta de la citada distribución. Es por tanto cuestión de investigación continuada cual de ambos procesos juega un papel más preponderante.

Pero para conocer la importancia de la selección natural en la evolución no basta, en principio, con saber cuál es el proceso más importante que dé cuenta de la distribución de variabilidad. Debemos saber, además, si las fuentes de variabilidad restringen o no el alcance de los procesos selectivos (Lewontin 1979). El neodarwinismo y la teoría neutralista de la evolución molecular afirman, al menos en parte, que para comprender el proceso evolutivo es suficiente con el conocimiento de los procesos de distribución de la variación. En la actualidad, la teoría de las restricciones endógenas es una alternativa tanto al neodarwinismo como 
al neutralismo, en el sentido de que contempla como necesaria la comprensión de los fenómenos relativos a los orígenes de las fuentes de variación.

\section{Naturaleza y cultura}

Hasta aquí he planteado la naturaleza del hecho evolutivo, el papel que la selección natural tiene en su gestación y la controversia en torno a la necesidad o no de recurrir a fuerzas endógenas para dar cuenta también del fenómeno evolutivo. Darwin se sirvió de los resultados de la selección artificial para formular, de forma análoga, el efecto de la selección natural en el resto de las especies. Pero el argumento de la selección artificial admite una reflexión más profunda, porque el hombre, producto de la evolución biológica, no solo la contempla y teoriza sobre ella, sino que está en condiciones de intervenir en ella, intervenir en la naturaleza.

El hombre es una singularidad evolutiva. No quiero con ello manifestar que otras especies no lo sean, pues ciertamente cada una de ellas dispone de caracteres diferenciales que contribuyen a su singularidad. Los caracteres de la nuestra, en cualquier caso, son particularmente singulares. Por ejemplo, el hombre tienen conciencia de su naturaleza, es consciente de su existencia y es capaz de contemplar, atónito o no, el proceso que lo ha llevado a ella. La evolución biológica no responde a un programa predeterminado donde la conciencia humana tuviera que venir a ser el producto final de la misma. La biología no hace buenas migas con el principio antrópico, ya que los diferentes linajes que han ido evolucionando a lo largo de la historia de la vida bien pudieran haber sido otros, y ciertamente los que ahora existen han evolucionado, entre otras cosas, a partir de condicionantes históricos y contingencias difícilmente previsibles. En otras palabras, el planeta podría estar poblado por seres otro tipo complejo de seres, aunque no necesariamente conscientes.

El hombre tiene capacidad para mirar retrospectivamente el tortuoso camino de la evolución. Es más, aspiramos a darle algún sentido al propio origen de la vida y al del hombre. Es más, algo nos impele a integrar tales aspiraciones en una cierta cosmovisión encaminada a dar sentido a todo. De hecho las cosmovisiones nos resultan necesarias desde el primer instante en que adquirimos conciencia de nuestro yo y también la capacidad de anticipar futuros, evaluando alternativas. 
Pero al tiempo que hemos llevado a cabo ese cuestionamiento, hemos también estado inmersos en un proceso de transformación de todo aquello que nos rodea y de nosotros mismo. La naturaleza - puede sostenerse- la hemos transformado. El desarrollo de la cultura en nuestra especie tiene una particular relevancia, es un elemento capital que ha permitido, de forma recursiva, la invención y proliferación de nuevas facultades que se han añadido a las propiamente biológicas. No es que tales facultades vayan al unísono o sean necesarimante complementarias con las invenciones biológicas de la especie en todos los casos. Pero lo cierto es que la cultura, como dimensión añadida a la evolución biológica, ha posibilitado que nuestra contemplación de la naturaleza no sea meramente pasiva, sino de transformación, de una transformación progresiva que comenzó en los albores de la especie, cuando empezamos a fabricar herramientas como prolongaciones de nuestras habilidades naturales o para suplir sus carencias.

La historia de la especie es la historia de la interacción entre la biología y la cultura (Castro Nogueira et al. 2008; Mosterin 2009), y ahora más que nunca podemos certificar que eso ha sido así. Buena parte de la tradición del pensamiento occidental ha hecho caso omiso al alcance de lo biológico en la especie, cuando ahora somos más conscientes que nunca que lo biológico ha estado y está presente en nuestro diario quehacer (Castrodeza 2009). El ámbito de los estudios humanísticos y sociales se ha circunscrito a lo humano en tanto que ser caente de naturaleza y considerado que la dimensión cultural, el contexto social, es lo que desde los primeros momentos de la especie ha estado imprimiendo ese estatus de singularidad al que hacía referencia anteriormente. Pero no es el caso, nuestra singularidad ya se estaba cociendo antes que la cultura cuajara. Además, tanto el lenguaje como la cultura son características con ventaja evolutiva, o al menos debieron tenerla cuando emergieron. Por otro lado, como suele ocurrir con las propiedades emergentes, nos han transportado a mundos radicalmente nuevos, mundos que solemos evaluar como progresivamente mancos de de naturaleza. El mundo de los humanos es un mundo que se ha fabricado con hallazgos biológicos fundamentales que, una vez aparecidos, nos ha puesto en una tesitura de vida progresivamente desnaturalizada.

Naturaleza y cultura, en efecto, forman un binomio inseparable; aunque del primero hayamos pasado al segundo y, una vez aparecido, el segundo interaccione de forma permanente con el primero. Pero: ¿hasta dónde hemos llegado? o, mejor, ¿̇hasta dónde podemos llegar? Si la reflexión filosófico-científica nos 
otorga naturaleza y nos conecta con un mundo que no nos puede ser ajeno por razones ontológicas (compartimos propiedades fundamentales con el resto de los seres), lo cierto es también que el proceso de transformación de lo natural por parte del hombre está llevando, y puede llevar más todavía, a una suerte de modificación de los seres que nos rodean y de nosotros mismos, transformando su estatus ontológico, desnaturalizándolo. No se trata de algo anecdótico, porque la transformación empezó cuando hicieron acto de presencia instrumentos y objetos modificadores o prolongadores de nuestra habilidades. Podemos percibir que el mundo cambia porque lo cambiamos y, en cambio, no tener conciencia tan inmediata de que nosotros estamos cambiando, algo que nos ocurre desde siempre. El reto, por lo tanto, es doble: primero, evaluar hasta donde hemos llegado y segundo, pensar hasta donde podemos llegar. ¿Qué futuro nos espera?

El binomio naturaleza-cultura podría sustituirse por este otro: natural-artificial. Nosotros somos seres naturales o, dicho de otro modo, en el contexto de la evolución hemos devenido un tipo particular de criatura con unas ciertas características producto de las fuerzas de la evolución. Pero al tiempo hemos desarrollado habilidades de intervención creciente sobre la propia dinámica de lo natural. No es sólo el que empezáramos inventando utensilios, cosa que hemos continuado de forma creciente, sino que hemos intervenido en los propios procesos de la naturaleza, de forma más o menos racional.

Nuestra tecnología, por rudimentaria que hubiera sido al principio, ha ido tomando cuerpo con el tiempo, se ha infiltrado hasta lo más recóndito de la sociedad humana. Esa tecnología define lo artificial, lo construido con un plan, lo dirigido, con más o menos eficiencia, a la obtención de algún resultado. Hemos domesticado especies, y hemos desarrollado técnicas maravillosas, y lo seguimos haciendo. El binomio natural-artificial nos caracteriza tanto o más que la propia naturaleza. De nuevo, ¿̧hasta dónde puede llegar esta dinámica de artificialización de lo natural? Quizás porque hemos contemplado atónitos nuestra propia naturaleza, y lo natural-otro (aquello natural que nos excluye) y nos hemos sentido desbordados por su magnitud, por su dimensión, por su exuberancia, no hemos sido particularmente conscientes de los efectos de la artificialización. Estaba ahí lo artificial para facilitarnos la vida, para incrementar nuestro bienesar, para lograr cotas de habitabilidad o, incluso, para digirirnos a otros y destruirlos al objeto de seguir incrementando nuestro nivel de satisfacción o simplemente nuestras probabilidades de supervivencia. El planeta lo hemos ido parcheando 
con enclaves pequeños de habitabilidad humana, con un crecimiento lento, y muchas veces sometido a debastadores procesos que mermaban el crecimiento de la especie, la mayor parte de las veces por epidemias, o incluso por un crecimiento local desmedido incompatible con los recursos naturales colindantes. Pero el parcheamiento esporádico fue tomando dimensiones de auténtica colonización planetaria y es a partir de entonces cuando más apreciamos la radical artificialización de nuestro entorno y nosotros mismos.

Si los términos del binomio natural-artificial pierden su nitidez es, en buena medida, debido a que lo artificial modifica lo natural, la tecnología altera lo natural y lo natural-otro. Pero, ¿podemos llegar a una alteración de rango ontológico? Al proceso de alteración ontológica de lo natural en nosotros por lo artificial, siguiendo un término ampliamente utilizado (Sádaba, 2009) lo denomino transhumanización y de ello quiero ocuparme. Pero también cabe considerar el proceso de alteración ontológica de lo natural-otro por la acción de la artificialización humana.

\section{Ontología de la intervención sobre lo natural}

Más adelante haré referencia a que el proceso de artificialización de nuestra naturaleza y de lo natural-otro se está transformando progresivamente en una intervención racional, con conocimiento cada vez más detallado. Esta tesis, no obstante, tiene una fuerte incidencia sobre el significado y alcance de la transhumanización y, por lo tanto, sobre el alcance de la naturalización en la historia de nuestra especie. Porque, en efecto, en nuestra historia, en toda nuestra historia, siempre ha existido un sustrato genético-biológico que condiciona nuestras posibilidades de existencia en el mundo - y cuando digo nuestras quiero indicar de todos y cada uno de nosotros- - He hecho referencia a la dinámica naturaleza-cultura y cómo esta última, en cualquier caso, en los seres particulares que somos nosotros, nos abre expectativas vitales y de supervivencia relativas, porque el mundo particular donde la ejercemos, como muy acertadamente sostiene Castrodeza (2009), es uno derecursos limitados, caulesquiera que ellos sean.

Pero es importante considerar la artificialización y la intervención como fenómenos que están muy presentes, particular y singularmente, en la historia de 
nuestra especie, y es muy legítimo preguntarse si existe o va a existir, dadas esas tendencias sostenidas en la dinámica de nuestra cultura, una oportunidad real de incidir en lo natural en nosotros y en lo natural-otro. Estar sometido al imperio de lo natural es, en otras palabras, aceptar de facto que el mundo está darwinizado (Castrodeza 2009). Y si el naturalismo impregna de forma más o menos consciente toda nuestra trayectoria vital, urge pensar si la artificialización podrá o no subvertir el orden, desconocido y difuso, aunque cada vez menos, que la naturalidad impone. Las consecuencias son importantes desde un punto de vista ontológico, porque cabe la posibilidad de imaginar un mundo no darwinizado o, dicho de otro modo, un mundo transhumanizado.

Cierto es que la adscripción de naturaleza al hombre ha supuesto un largo recorrido, y Darwin tiene el complicado privilegio de haber abierto la caja de los truenos de este proceso de incardinación de nuestra evolución en la del resto de seres. Pero también es cierto que gozamos de ciertas singularidades, siendo la autoconciencia una de las más notorias. Y es particularmente relevante porque supone la base sobre la que percibimos que somos algo, que la existencia evolutiva ha propiciado la aparición de un ente que es, un ente natural, ciertamente. Ese ser tan singular probablemente sea el único que puede decir de sí mismo que es y, por lo tanto, gozar de una singular presencia frente a otros seres de la naturaleza que no pueden decir de sí mismos que son. Castrodeza (2009) hace una excelente reflexión donde justifica la primera ontología de Heidegger en Ser y tiempo en términos de la evolución biológica que tiene en el hombre un singular producto. En cualquier caso, y para mis propósitos, cabe formular la siguiente tesis: la pérdida del ser heideggeriana, ese apartarnos de nuestra primerísima percepción que caracteriza nuestra historia, no representa más que un estado de transición hacia otro ser. La eventual pérdida puede contener un elemento renovador, de subversión contra es naturaleza que nos somete, porque no somos más que sujetos expuestos al dictamen de nuestros genes en un mundo multifacético compuesto por recursos escasos que son objeto de sus intereses. ¿Podremos subvertir el orden natural-genético por la propia artificializacion? Es posible que estemos en el camino de la construcción de seres ontológicamente tan relevantes como los humanos en tanto que perceptores de su existencia, pero no naturales. ¿Qué o quien puede permitir tal advenimiento? La tecnología, que de la mano de la ciencia ha ido transformando lo natural y lo natural-otro, implementando artificialización creciente que deviene finalmente intervención racional. 
La ciencia explica y da fundamento a la tecnología, y la capacidad de ella de fundamentar racionalmente, con pensamiento bien fundado y progresivamente más sustancial, más omnicomprensivo, los procesos de artificialización del mundo a manos nuestras está en la base de nuestra posible transformación ontológica o, dicho de otro modo, está en la base de la eventual aparición de nuevos entes y de nuevos seres. Ellos no necesariamente serán naturales y, en todo caso, podrán dictar su destino de forma plena, porque no estarán sometidos al dictum de su naturaleza genético-biológica, si estamos hablando de alguna tipología con cierta base biológica. No serán sus genes quienes jueguen con ellos, sino ellos quienes jueguen con sus genes. En la medida en que esa naturalidad sea subvertida, dominada, comprendida, modificada, estamos hablando de un estadio de la historia de la vida donde el hombre será superado, un estadio de transhumanización que, en el ámbito de la ontología comporta un nuevo retorno primigíneo al dasein de Heidegger.

\section{Seres artificiales}

No es un futurible la posibilidad de alterar del estatus ontológico de nuestra especie en una suerte de ejercicio de evolución sobrevenido, en modo alguno una continuidad de la evolución biológica sino, en todo caso, de su progresivo aminoramiento y eventual reemplazamiento por un modo de intervencionismo controlado, postevolutivo. El conocimiento científico y las tecnologías desarrolladas en relación con el intervencionismo humano durante las últimas décadas son tan abrumadores que a duras penas podemos hacer un vaticinio de qué nos van a deparar el futuro más o menos inmediato. Es importante establecer un paralelismo, una metáfora útil si se quiere, entre la imprevisibilidad evolutiva en la historia de la vida del planeta y la imprevisión del tipo de intervenciones que, en última instancia, son las que se van a imponer. En cualquier caso, y a efectos meramente didácticos, se puede establecer una tipología de intervenciones que aglutinen la enorme casuística que viene desarrollándose desde el origen de nuestra especie.

Tres son las tipologías fundamentales. La primera es la robotización, es decir, el desarrollo de entes mecánicos progresivamente más próximos en su comportamiento a la especie humana. La segunda consiste en la cyborgización, donde lo que se pretende es integrar implantes de naturaleza variada en el propio ser humano con la finalidad de generar entes bio-mecánicos. Y la tercera se vincula al desa- 
rrollo de la cibermundialización, donde cabe la posibilidad de la emergencia de entes en el ciberespacio con capacidad de emular el comportamiento humano.

No se nos puede escapar la connotación antropocéntrica que las tres aproximaciones comportan. En el caso de la robotización o la cibermundialización se tiene a la especie humana como objetivo, pues o bien se parte de diseños, dispositivos, mecanismos que de forma más o menos progresiva desarrollan propiedades humanas (robotización) o bien, en el caso de la cibermundialización, estamos esperando la emergencia de alguna de las características básicas de nuestra especie como puedan ser las emociones o la inteligencia. Y en el caso de la cyborgización la especie humana es el punto de partida, la entidad sobre la que se va a actuar para efectuar implantes de naturaleza artificial. Pero existe un nexo común entre las tres tipologías, a saber: que la naturaleza del producto que se va obteniendo es de un estatus ontológico nuevo. La artificialización va diluyendo la ontología del ser natural en el caso de la ciborgización, difícilmente podemos atribuir un estatus de ontología natural al robot completamente humanizado en el caso de la robotización y, finalmente, la cibermundialización tiene, de partida, un estatus platónico con respecto al ser natural que pretende emular.

De una forma y otra, las tres tipologías, aunque tengan como punto de partida al hombre, pueden superarlo. Son esencialmente transhumanas porque las tres pueden acabar en entes radicalmente nuevos; es más, los entes procedentes de esas tipologías no tienen por qué ser coincidentes en sus fases más elaboradas, y esa fase transhumana puede estar formada por una plétora de seres ontológicamente no humanos, pero distintos a su vez. Como podrá apreciarse, se trata de una postevolución que evoluciona de forma diferente, o con reglas intrínsecamente distintas a las que modulan la evolución biológica. Cuestión otra es la relación que nuestra especie pueda o deba ir manteniendo con estas entidades conforme vayan emergiendo.

En efecto, no me muevo bajo la premisa de que el mundo que nos espera va a ser uno dominado por seres que hemos creado y donde, probablemente, nosotros pasemos a una situación de deterioro progresivo hasta la eventual desaparición. Esto, no obstante, es una hipótesis que cabe contemplar y según la cual, por cierto, hay que matizar que no necesariamente todos y cada uno de los transhumanos vayan a ser productos o engendros de nuestra creación. Es muy pertinente formular la observación de que cabe la posibilidad, bien fundada en los 
teoremas de Gödel, de la emergencia de entes totalmente inexplicables en los términos de las reglas de diseño y construcción con las que estamos operando en la actualidad en las tres grandes tipologías comentadas.

\section{Agradecimientos}

Ese trabajo ha sido financiado por el proyecto europeo TARPOL, FP7/20072013, contrato n. 212894 y el proyecto Prometeo 2009/092 de la Generalitat Valenciana.

\section{Bibliografía}

BOWLER, P., 1985. El eclipse del darwinismo. Barcelona: Labor.

Castrodeza, C., 2009. La darwinización del mundo. Barcelona: Herder.

Castro Nogueira, L., Castro Nogueira, L. y Castro Nogueira, M.A., 2008. ¿Quién teme a la naturaleza humana? Madrid: Tecnos.

DARWIN, C. 1859. The Origin of Species, traducción española: El origen de las especies, Madrid: Edaf, 1970.

EndLer, J. A. 1986. Natural Selection in the Wild. Princeton, New Jersey: Princeton University Press,

LEWONTIN, R.C., 1979. La base genética de la evolución. Barcelona: Omega.

MendeL, G.J., 1886. Experimentos de hibridación en plantas. Editado por J.R. LACADENA en En el centenario de Mendel: la genética ayer y hoy. Madrid: Alhambra, 1983.

Mosterín, J., 2009. La cultura humana. Madrid: Espasa Calpe.

Reichenbach, H., 1967. La filosofía cientifica. México: Fondo de Cultura Económica.

SÁdabA, I., 2009. Cyborg. Sueños y pesadillas de las tecnologías. Barcelona: Península.

SOBER, E., 1984. TheNature of Selection. Cambridge: MIT Press.

Toulmin, S., 1977. La comprensión humana I: el uso colectivo de la evolución de los conceptos. Madrid: Alianza Universidad.

Recibido: 17/09/2009

Revisado: 5/10/2009 